\title{
USO CÓMICO Y 'DRAMÁTICO’ DE LA IRONÍA SITUACIONAL EN LOS CUENTOS DE SAMUEL ROVINSKI: EL CASO DE "DELICIAS DEL VUELO" Y "CAMBIO DE IDENTIDAD"
}

\author{
A HUMOROUS AND DRAMATIC APPLICATION OF SITUATIONAL IRONY IN \\ SAMUEL ROVINSKI'S SHORT STORIES: "DELICIAS DEL VUELO” \\ AND “CAMBIO DE IDENTIDAD”**
}

\section{Dorde Cuvardic García*}

\begin{abstract}
RESUMEN
El propósito del presente artículo ponencia es analizar la ironía de situación como recurso narrativo en algunos cuentos de Samuel Rovinski. El cuento se define por su efecto (como también ocurre con la poesía) y la ironía de situación se revela como un importante procedimiento que permite alcanzar el propósito buscado por el autor. En algunos casos, tiene finalidad humorística, como en el cuento "Delicias del vuelo", de El embudo de Pandora. En otras ocasiones, como en Cuentos judios de mi tierra, la ironía de situación, desde una finalidad dramática o existencial, permite comprender de manera más clara el absurdo de la discriminación que sufren las minorías. Es el caso de "Cambio de identidad", donde el narrador sufre la paradoja del pueblo judío en Occidente: la tierra de acogida se revela sólo como una escala más hacia un exilio interminable.

Palabras clave: Literatura costarricense, cuento, Samuel Rovinski, ironía de situación, discriminación y exilio, comicidad.
\end{abstract}

\begin{abstract}
**
This article aims to analyze situational irony as a narrative element in some of Samuel Rovinski's short stories. A short story is -as well as poetry- analyzed based on its effect, and situational irony is revealed as an important procedure that allows the writer to achieve his/her purpose. Sometimes, this goal may be to add humor, such as in "Delicias del vuelo", in El embudo de Pandora. On the other hand, in Cuentos judíos de mi tierra, for instance, situational irony may, from a dramatic or existential objective, help to understand from a clearer perspective how absurd discrimination against minorities is. Such is the case, in "Cambio de identidad," in which the narrator undergoes the paradox of the Jewish people in the West, where the hosting land rebels just to become a new step in an endless exile.
\end{abstract}

Key Words: Costa Rican Literature, short story, Samuel Rovinski, situational irony, discrimination, exile, humor. 


\section{Introducción}

Al ocuparse de la obra de Rovinski, la crítica literaria y las historias de la literatura costarricense de los últimos cincuenta años se concentran en sus novelas y obras teatrales. La única colección de cuentos que ha recibido atención crítica es Cuentos judios de mi tierra, analizada e interpretada por Alberto Barahona en su tesis de licenciatura (subtitulada El viaje interminable de la identidad versus la alteridad, 1991), que ha publicado en diversos artículos (2003). La identidad de una minoría, la judía, es el tema principal de su investigación.

Nuestro propósito es estudiar algunos cuentos de Rovinski desde otro encuadre interpretativo, la ironía de situación, un excelente recurso narrativo con el que cuenta todo escritor para alcanzar el principal efecto del conciso género del cuento: la sorpresa. Asociada tradicionalmente a la tragedia griega, la ironía de situación es clave para obtener el tono humorístico o trágico que los narradores contemporáneos quieren conferir a la representación narrativa acontecimientos humanos. Un ejemplo se ofrece en la construcción o estructuración de las noticias. Cuvardic (2013; en prensa), aporta una exhaustiva clasificación de recursos en el artículo "Marcadores de ironía en el discurso informativo de la prensa costarricense". Entre estos marcadores, Cuvardic ha identificado casos de ironía situacional en el género de las llamadas notas curiosas, como en los siguientes titulares: "Presidiarios se fugan de la cárcel más segura" " "Cayó muerto en la propia puerta del hospital ${ }^{2 "}$ o "Atropellado se pega el gordo de la navideña" ${ }^{3}$ ".

El objetivo de este artículo es analizar el funcionamiento del recurso narrativo de la ironía de situación en los cuentos "Delicias del vuelo", de El embudo de Pandora (1991) y "Cambio de identidad", de Cuentos judios de mi tierra. En el primer caso, desmenuzar el funcionamiento de esta modalidad de ironía en un cuento humorístico proporciona una herramienta productiva para su utilización en los talleres de creatividad literaria. En el segundo caso, la ironía de situación permite comprender las situaciones paradójicas que las minorías sufren como víctimas de sociedades autoritarias.

Los dos cuentos son retrospectivos: en ambos casos, el personaje protagonista, mediante un proceso autorreflexivo de toma de conciencia, reevalúa irónicamente una experiencia o proceso personal. Aunque en el primer caso, "Delicias del vuelo", la ironía de situación se utiliza con fines cómicos y, en el segundo caso, "Cambio de identidad", con fines 'trágicos', una similitud se ofrece en ambos relatos: las experiencias personales quedan reevaluadas, desde el presente de la enunciación del personaje protagonista, como una concatenación de situaciones absurdas, hostiles.

\section{La ironía de situación desde la teoría literaria}

La ironía de situación ha sido definida como la existencia de una incongruencia

"que surge de la tensión entre lo que se espera o se pretende y lo que realmente sucede." (Li, 2008: 5). Es identificada cuando se presenta una desbalance o desequilibrio entre las expectativas y los resultados ${ }^{4}$. A nivel narrativo, la protagonizan aquellas personas que experimentan situaciones que contradicen las previsiones o lo que se considera el orden del mundo (Schoentjes, 2.003: 45-65). Ya analizada por Aristóteles en su Poética con el nombre de peripecia, no sólo alude al imprevisto empeoramiento de la situación de un personaje (así, por ejemplo, durante el Romanticismo se culpará al destino o al sino de las desgracias propias), sino también a su inesperado mejoramiento.

El principio de negación (A no significa A, sino B), también formulado como principio de contradicción, opera tanto en la ironía verbal como en la situacional. En el primer caso, el significado del enunciado explícito o trópico es opuesto, semánticamente, al significado del enunciado intencional implícito o literal, 
mientras que en el segundo caso, una situación que inicialmente se consideró como fija o estable se revela finalmente como su opuesta, como caótica e inestable. Sobre esta semejanza, Lucariello (1994: 129) explica que tanto la ironía verbal como la situacional exhiben una dualidad, una oposición de términos, una yuxtaposición de incompatibilidades, entre lo dicho o literal y lo implícito, en el caso de la verbal, y entre lo que ocurrió y lo que en un principio se esperaba que ocurriera, en el caso de la situacional.

Schoentjes (2003: 49), al definir la modalidad de lo que llama ironía de situación narrativa, precisa que el cambio implicado que se resuelve contra nuestras expectativas, por lo que juega con el tema de la identidad oculta y la distancia entre el ser y el parecer ${ }^{5}$. Permite desestabilizar nuestras creencias en las identidades fijas: pensamos tener el control del mundo (la apariencia) e, inesperadamente, sale a la superficie el caos y el desorden que, finalmente, domina sobre el mundo o la existencia humana (el ser). Supone, sobre todo, una inversión narrativa ${ }^{6}$, y tiene un carácter no premeditado: los acontecimientos no evolucionan como pensábamos en un principio que lo iban a hacer ${ }^{7}$. Todo quiebre de expectativas, o el acontecimiento que está en contradicción con lo previsto o lo que se considera el orden de la existencia humana (Schoenjes, 2003: 47) generará sorpresa $\mathrm{y}$, por lo tanto, interés.

En los últimos años se han desarrollado teorías que buscan comprender el funcionamiento de la ironía de situación desde la narratología cognitiva (y, por ende, desde la psicología cognitiva). Un concepto importante de este enfoque para comprender la ironía de situación es el de guión [script]: toda narración tiene un esqueleto estructural o guión (en otras palabras, sigue un modelo narrativo). Aparece la ironía cuando se opera un alejamiento imprevisto de este último ${ }^{8}$. Como señala Li (2008: 8): "El reconocimiento de las ironías situacionales surge cuando un conjunto de situaciones se desvía irónicamente de nuestros guiones."

La ironía situacional tiene que ser identificada, como procedimiento del relato, a partir de los hechos transcurridos. En la práctica literaria, por lo general, dos agentes pueden realizar esta acción: el lector, que identifica como irónica la situación que vive o ha vivido el protagonista, y el propio protagonista del acontecimiento (en ocasiones narrador en primera persona) o un personaje intradiegético. Ambos sujetos, testigos de los hechos, pueden reflexionar retrospectivamente sobre su condición irónica. En la producción de la ironía verbal hay un ironista que usa premeditadamente este recurso retórico (Lucariello, 1994: 129), mientras que la ironía de situación no es producida intencionalmente, sino identificada en una situación: un observador o un agente reflexivo etiqueta una situación como irónica. Toda ironía situacional es retrospectiva: no se puede identificar el acontecimiento como irónico antes o durante el mismo. Muecke (en Lucariello, 1994: 129), destaca que, cuando el enunciador emite una ironía verbal, el observador dice "El o ella está siendo irónico", mientras que, ante una situación identificada como irónica, declara este último "Es irónico que....". Es el observador o la víctima quien, mediante un proceso analítico logra identificar atributos irónicos en una situación. Formula la siguiente reflexión: 'yo considero irónico que, en este tipo de situación, donde regularmente se dan este tipo de circunstancias, se den otras'.

Lucariello (1994: 131), para operacionalizar y clasificar la ironía situacional, identifica cuatro de sus cualidades o atributos. En primer lugar, debe presentarse una situación inesperada, repentina, imprevista; en segundo lugar, esta situación debe destacar la fragilidad de la condición humana; en tercer lugar, el resultado del acontecimiento debe resultar en una ganancia o en una pérdida para su protagonista $y$, en cuarto lugar, debe ofrecer una contradicción o inconsistencia en el comportamiento o conducta de personas, individuos o instituciones (la segunda acción o situación cancela, negándola, una primera acción o intención ${ }^{9}$ ). Sobre este último atributo, recordemos que los principios de negación y de contradicción gobiernan la construcción y recepción de la ironía, tanto de la verbal como de la situacional. 
En numerosas ocasiones, el resultado de la ironía de situación es negativo, es decir, la situación conlleva una pérdida para su protagonista. Es el caso de la peripecia o cambio en el destino del personaje que pasa de la felicidad a la desgracia. El acontecimiento identificado como irónico (por un testigo u observador, en el que podemos incorporar al lector) o por el mismo protagonista del hecho (una vez que ha reflexionado sobre las implicaciones de este último) involucra el hecho de percibir o comprender la existencia como un conjunto de experiencias que, frente a las previsiones y expectativas, se encuentran fuera de control del ser humano. Como explica Lucariello (1994: 129), la ironía de situación

otorga atención a aquellas situaciones que no debieron ocurrir. Es una explicación de las anomalías que se presentan en la actividad humana. En otras palabras, se podría pensar como una explicación de la poca confiabilidad que podemos otorgar al mundo. Expresa nuestra conciencia de que no podemos confiar en nosotros mismos, o en los demás, o en acontecimientos que siguen un curso normal. [...] nos indica la vulnerabilidad de la condición humana.

Considero que la autoironía, identificable en el cuento "Delicias del vuelo", también se puede entender como ironía de situación, cuando la víctima de esta última reflexiona retrospectivamente sobre la experiencia que ha tenido. Como señalan Sperber $\mathrm{y}$ Wilson (1994: 290-296), la autoironía es un enunciado de eco: nos hacemos eco de puntos de vista que respaldamos en el pasado de manera inquebrantable, pero que actualmente consideramos irrisorios. Baudelaire mismo, en Esencia de la risa (1855), reevalúa esta actitud o disposición, desde el punto de vista de la propia víctima. Primero, Baudelaire explica la causa de la risa surgida ante la contemplación de la desgracia ajena, al narrar la situación de una persona que sale de su casa, dispuesta a 'comerse' el mundo, y tropieza. El observador desarrolla un sentimiento de superioridad: "se hallará en el fondo mental del reidor un cierto orgullo inconsciente. Este es el punto de partida; yo no caigo; yo ando derecho; yo, mi pie, es firme y seguro. No seré yo quien cometa la tontería de no ver el bordillo de la cera o la piedra del camino." (en cursiva en el original) (Baudelaire, 2001: 87-88). Páginas después reconsidera esta situación desde la posibilidad de que sea la propia víctima la que ría, en los casos donde la caída se encuentre acompañada de una actitud autorreflexiva por parte de su protagonista: "No es el hombre que cae quien ríe de su propia caída, a menos que sea un filósofo; es decir, un hombre que haya adquirido por hábito la fuerza de desdoblarse rápidamente, para asistir como espectador desinteresado a los fenómenos de su yo." (Baudelaire, 2001: 89).

El escritor francés designa con el concepto 'cómico absoluto' estos casos de autoconciencia irónica. En términos bajtinianos, la autoironía en un caso de dialogismo interno. El individuo que tropieza, y que toma conciencia de los fracasos que puede llegar a sufrir en su cotidianeidad, se hace 'eco' -y se ríe- de la previa predisposición, prepotente, con la que salió de casa, antes de tropezar. Se trata de un sujeto que, para reírse de sí mismo, debe desdoblarse. Crea un enunciador crítico y burlón que observa desde una superioridad distanciada al sujeto que tropieza (él mismo, pero ya objetivado, convertido en un otro 'externo'): este enunciador imaginario observa cómo se han hecho 'añicos' las expectativas autosuficientes de la víctima material del tropiezo ${ }^{10}$.

\section{La ironía de situación al servicio de la comicidad en "Delicias del vuelo", de El embudo de Pandora}

En el cuento "Delicias del vuelo", las distintas situaciones vividas por el protagonista durante un viaje en avión que cubre el trayecto París-San José son manifestaciones de la ironía de situación. El efecto de comicidad se elabora a partir de una situación humana universal, no necesariamente circunscrita a la realidad costarricense.

En este cuento no sólo se utiliza la inversión de las expectativas de la ironía de situación. La ironía verbal, en su modalidad 
de antífrasis, de inversión semántica, ya se ofrece desde el título del cuento, "Delicias del vuelo": es un paratexto irónico que introduce un texto en el que se relatarán, más bien, las adversidades de un pasajero.

El viaje en avión es, en el relato literario, cinematográfico y televisivo, un motivo que en numerosas ocasiones ha sido narrado desde el recurso que nos ocupa en el presente artículo. El hecho de que diversas personas, desconocidas entre sí, se encuentren obligadas a convivir en un estrecho espacio -aunque sea por un limitado marco temporal- facilita la aparición de situaciones cómicas. La ironía de situación surge cuando los pasajeros contravienen los códigos de sociabilidad $-\mathrm{y}$, por lo tanto, las expectativas sobre el protocolo de la convivencia en público- que previsiblemente deben tomar entre sí desconocidos obligados a convivir por un periodo limitado de tiempo. Ejemplo conocido lo ofrece el episodio "On the plane" de la serie Seinfeld, que narra la tortura que supone para Elaine viajar en clase turista y a Jerry Seinfeld el eximio placer que le depara sentarse en primera clase. Asimismo, Aterriza como puedas (1980) es otro filme clásico lleno de ironías de situación. Esta visión humorística del viaje en avión, sobre todo si el desplazamiento se realiza en clase turista, cuenta con precursores literarios. La literatura costumbrista del siglo XIX registró en multitud de sketch las incomodidades que los pasajeros sufrían en los estrechos asientos de la diligencia, si el viaje se realizaba en los pésimos caminos del espacio rural, o en el ómnibus, el primer transporte colectivo urbano, introducido por vez primera en París en el año 1828.

El vuelo en avión, como cronotopo, se caracteriza por una corta temporalidad (escasas horas) y una restringida espacialidad (los escasos metros cuadrados de la cabina de pasajeros de un avión). Desde estos criterios, se encuentra en las antípodas del moroso cronotopo del camino, caracterizado por una extensa temporalidad y espacialidad. La convivencia forzada en un exiguo lugar favorece la creación de situaciones humorísticas, frente a la seriedad y trascendencia idealista de los amplios horizontes espaciales y temporales de la épica.
Como ya dijimos, la ironía situacional, cuando es identificada por los personajes, es retrospectiva. La víctima de la ironía de situación se encuentra, como espectador, en capacidad de evaluar los acontecimientos ocurridos. El relato que nos ofrece el narrador del cuento de Rovinski tiene esta orientación hacia el pasado. Desde el primer párrafo, y antes de que relate las situaciones que vivió durante el vuelo, ya sugiere al lector que sus expectativas sobre el viaje finalmente no se cumplieron. Dice al inicio del cuento que fue recibido por dos funcionarios de Aeroflot, "en lo que prometía ser un vuelo de rutina" $\left(80^{11}\right)$. El lector actualiza la continuación de la frase, que se extrae por implicatura: "en lo que prometía ser un vuelo de rutina... que nunca lo fue".

La comodidad es una de las expectativas que busca alcanzar todo pasajero. El narrador del cuento se enfrenta a su inversión: el viaje representó una de las mayores 'torturas' que recuerda. ¿Qué situaciones incómodas sufre? Nada más entrar en el avión no puede sentarse con su esposa en asientos contiguos, contra sus expectativas. Poco después, encuentra lugar al lado de una hermosa mujer rusa. Con la expectativa de tener una conversación agradable con ella, el narrador relata su alegría al considerar la suerte que le ha tocado. La rusa se revela, sin embargo, como una habladora desmesurada que no cierra la boca durante todo el vuelo, conducta que sólo se resuelve bien avanzado el viaje, cuando la amordaza en el baño. Este personaje femenino se encuentra en las antípodas de representado en "El avión de la bella durmiente", escrito en 1982, perteneciente a la colección Doce cuentos peregrinos, de Gabriel García Márquez, donde se actualiza el personaje de la bella durmiente en una pasajera sentada al lado del narrador"12: "la contemplé palmo a palmo durante varias horas" (García Márquez, 1997: 65). Ofrece un clásico motivo voyeurista de la historia de la literatura, el de la mirada arrobada de un personaje masculino heterosexual hacia una mujer dormida. El estereotipo de la belleza contemplativa remite, precisamente, a una mujer silenciosa (en realidad, silenciada), o por lo menos contenida verbalmente, objeto del deseo 
de la mirada masculina, siempre atenta a ofrecer una imagen 'sublime'. Contra las expectativas, el narrador de "Delicias del vuelo" se encuentra, en cambio, en lo que podemos considerar como la inversión irónica de esta imagen patriarcal, con una belleza parlanchina. Esta es otra expectativa frustrada del narrador: desde siempre se ha asociado la incontinencia verbal a estereotipos femeninos como la coqueta o la solterona, pero no a la joven seductora, que como estereotipo debería 'hablar', en principio, con una mirada y unos gestos sugerentes. La esposa del narrador, en cambio, tuvo como vecina a otra mujer rusa que no habló durante todo el trayecto: "muchas horas después descubriría que mi esposa había encontrado, en la Matriozka, una excelente compañera de viaje, de esas que todo viajero consciente sueña con tener a su lado: no soltó una palabra en todo el trayecto" (81).

Además, la pasajera rusa no sólo se revela como parlanchina, sino también como una hambrienta que devora la comida. Se quiebra otra de las expectativas del narrador, la de comer una suculenta comida durante el vuelo. No prueba bocado, abrumado por el torrente de palabras de la vecina, esta última infiere que el narrador no tiene hambre y comienza a comer de su bandeja.

Los dos cuentos, el de de Rovinski y el de García Márquez, los dos desde sus propuestas respectivas, problematizan la asunción de la mujer como objeto del deseo de la mirada masculina. En este sentido, el cuento del autor costarricense, aunque desde cierta lectura se pueda interpretar como un relato que reproduce el estereotipo de la mujer parlanchina, que habla 'por los codos', por otro lado nos ofrece, desde una perspectiva crítica, la deconstrucción de las expectativas patriarcales del hombre que, imbuido de autosuficiencia y vanidad, cree de antemano que cortejará con éxito a toda desconocida que, por azar, se encuentre sentada a la par, en cualquier tipo de transporte público. En el caso que nos ocupa, la "belleza contemplativa", estereotipo que esperaba encontrar el narrador, se revela como una "máquina parlante". Se ha dicho que la función pragmática de la ironía es correctiva $\mathrm{y}$, en este sentido, también se puede aplicar a la de situación, ya que nos permite redimensionar el punto de vista utilizado por el ser humano para encarar el entorno social: víctima de una inversión en sus expectativas, el hombre reevaluará los presupuestos que utiliza cotidianamente para entrar en comunicación con las mujeres, en el marco de las relaciones de anonimato. Como ejemplo de autoironía, el narrador, desde el presente de la enunciación, y en términos retrospectivos, recuerda su 'caída moral', desde su autosuficiencia inicial hasta su sometimiento final. El recurso de la ironía de situación se convierte, así, en un aliado para ridiculizar las pretensiones machistas de los personajes masculinos, como ocurre en el cuento de Rovinski, donde el narrador acaba siendo sometido por la contraparte femenina.

Del sentimiento de dominio inicial, el narrador siente una sensación de esclavitud, encierro y asfixia. Henry Bergson (1973: 70) utiliza la imagen del títere para visualizar lo que llama lo cómico en las situaciones: en muchas comedias, el personaje cree hablar y obrar con libertad, cuando más bien es un simple juguete y el objeto de diversión de la contraparte. Es lo que sucede en el cuento de Rovinski: el narrador es un títere cuyos hilos son manejados, a voluntad, por la pasajera rusa.

Otra imagen de lo cómico en las situaciones explicada por Bergson también nos permite perfilar con mayor detenimiento la ironía de situación que 'sufre' el narrador en manos de la bella rusa. La imagen de la bola de nieve sugiere el efecto cómico que tienen una serie de acontecimientos consecutivos, efecto acrecentado durante su propagación, "de modo que la causa, insignificante en un principio, alcanza, mediante un progreso necesario, un resultado tan importante como inesperado." (Bergson, 1973: 72-73). La imagen de la bola de nieve se puede traducir bajo el dicho 'las desgracias nunca vienen solas'. Cuando surge un contratiempo, se espera superar este último inmediatamente. Pero en muchos casos, un contratiempo viene acompañado de otros, y todos ellos ocurren en cadena. En el cuento de Rovinski, las consecuencias que desencadenará en el narrador la acción de sentarse junto con 
una mujer rusa serán numerosas e imprevisibles: el vuelo se convertirá para él en una tortura, víctima de una serie irrefrenable de conductas hiperbólicas protagonizadas por la pasajera.

Por último, una última imagen cómica explicada por Bergson, propia de la ironía de situación y presente en "Delicias del vuelo", es la inversión de papeles. Se trata de una situación que se revela contra aquel sujeto que la ha creado, del contratiempo que ha buscado uno por su propia culpa, de las redes en las que cae aquella persona que primero las arrojó (Bergson, 1973: 82-83). El narrador, que inicialmente tuvo la intención de galantear con su vecina y de pasar, durante el vuelo, un momento agradable, acaba por convertirse en su prisionero. De potencial sujeto dominante pasa a ser el 'objeto' sometido.

El efecto sorpresa, procedimiento tradicional del género del cuento, como ya hizo ver Edgar Allan Poe, -en su reseña a los Cuentos dos veces contados ${ }^{13}$, de Nathaniel Hawthorne- y que supone un mecanismo más para expresar la anulación de las expectativas, se produce cuando comprueba el narrador al final del cuento $-y$ junto con él el lector- que el señor obeso sentado al otro lado de la mujer rusa durante todo el viaje era su marido: "Me agradecía, en fin, por haber soportado la charla de Masha y haberle procurado las mejores nueve horas de su vida." (91). Es así como el lector, retrospectivamente, entiende el desapego con el que este vecino respondió al intento del narrador de entablar contacto con él, con el propósito de despegarse de la 'cháchara' de la mujer: "yo había recurrido a mi vecino en busca de ayuda, mediante significativas miradas. Pero infructuosamente; no pude captar su atención en ningún momento.” (85). Lo menos que quería este hombre era sostener conversación con un desconocido y abandonar los únicos momentos de silencio que podía disfrutar desde hacía mucho tiempo, después de sufrir cotidianamente el monólogo de su mujer.

El narrador tiene conciencia, desde el presente de la enunciación, de la condición cómica de los acontecimientos vividos durante el vuelo. La comprensión irónica que tiene de los hechos es la táctica que utiliza para otorgar un sentido, una vez que ya han tenido lugar, a la aparición de una serie de situaciones imprevistas. La interpretación irónica de su experiencia en el vuelo, supone, para él, una catarsis, en particular, una catarsis cómica, una manera de racionalizar y distanciarse de un encadenamiento de situaciones inexplicables.

\section{La ironía de situación en "Cambio de identidad", de Cuentos judíos de mi tierra}

Podemos entender cada uno de los Cuentos judíos de mi tierra (1982) como capítulos de una narrativa mayor, como ha destacado Barahona (1991: 123; 2003: 24) en dos oportunidades.

El título de la colección, Cuentos judios de mi tierra, puede ser entendido en términos paradójicos, si entendemos que esta tierra es la costarricense. Una vez leídos los cuentos, el sintagma 'mi tierra' se perfila desde una significación irónica, si el lector asume que el adjetivo posesivo se refiere a un integrante de la comunidad judía costarricense. Desde el punto de vista del desarrollo narrativo de la totalidad de los cuentos, la mayor ironía situacional se presenta cuando la tierra que se apreciaba inicialmente como una tierra de acogida o de refugio, desde las expectativas de los judíos emigrantes y exiliados procedentes de Europa, se revela en última instancia, en "Cambio de identidad", el último cuento de la colección, como un espacio transitorio que promueve su expulsión. Barahona (1991: 123), en este sentido, considera que, en el marco del desarrollo narrativo del conjunto de los relatos, se pasa de la euforia a la resignación.

El título de la colección también se puede entender como una paradoja desde el concepto genettiano de la arquitextualidad. Recordemos que un título puede expresar este tipo de relación cuando se incorpora el género o la modalidad discursiva del texto en el mismo paratexto, convertido en un programador de lectura, como sucede con los Cuentos de mi tía Panchita, de Carmen Lyra, o con los mismos Cuentos judios 
de mi tierra, de Rovinski. ¿Se puede decir que en tierras costarricenses se ha desarrollado una tradición cultural judía como para que podamos hablar del desarrollo de una literatura hebrea (cuentos, en este caso), como subsistema literario propio integrado en un sistema mayor, el literario costarricense?; ¿son cuentos judíos que pertenecen a la tradición hebrea, que conservan o actualizan su imaginario cultural, o son más bien cuentos simplemente protagonizados por individuos de religión judía, pero en los que llega a prevalecer una identidad nacional costarricense?

Cabe plantear una última pregunta. Podríamos inferir que el enunciador del título de la colección considera su tierra como la costarricense. Sobre esta base, ¿la identidad judía de estos cuentos la interpreta este enunciador como propia o como ajena? Considero que, ya sea que el adjetivo posesivo se encuentre enunciado por un judío o por alguien algún exterior a esta última comunidad, el complemento nominal 'de mi tierra' parece indicar que la tradición y la literatura judías ('cuentos') forman parte del sistema cultural literario costarricense, como también podría ser el caso de una categoría literaria que fuera designada con la etiqueta 'cuentos judíos de mi tierra ucraniana', por utilizar otro ejemplo.

La ironía favorecida por situaciones de multiculturalidad ha sido poco investigada. Una excepción procede de Roca Marín (2009) que, por lo demás, se concentra en la comprensión de la ironía en conversaciones interculturales. No se ha investigado, en cambio, la visión paradójica de la existencia que tienen, en cambio, las minorías en sociedades hegemónicas monoculturales. El cuento "Cambio de identidad", nos ofrece, en este sentido, varios casos de ironía situacional. Ofrece aquellas situaciones paradójicas sufridas generalmente por los integrantes de las minorías en sociedades hegemónicas que les definen desde la Otredad. El narrador valora como una serie concatenada de situaciones absurdas, desde el presente de la enunciación, retrospectivamente, su participación en la Guerra del 48 desde las filas del ejército gubernamental. En primer lugar, reflexiona sobre la ironía de ser judío en una tierra de cristianos, convertido en chivo expiatorio de la mayor parte de todos los problemas sociales. El sujeto que pertenece a una minoría, sobre todo si es inmigrante, enfrenta una primera ironía situacional: se 'mata' a trabajar, y se le etiqueta de vago; contribuye a levantar la riqueza de un país, y se le acusa de empobrecer a los 'nativos'. La ironía se basa en el principio de la negación, tanto a nivel retórico (en el marco de una palabra) como a nivel discursivo, y la discriminación contra las minorías se fundamenta, precisamente, en la negación de las cualidades que poseen o que, como cualquier otro sujeto humano, tienen la potencialidad de desarrollar. Recordemos una de las esquinas del cuadrado ideólogo, procedimiento metodológico del análisis crítico del discurso: es típico de todo discurso autoritario atenuar o negar las virtudes del exogrupo, del Ellos. El narrador de "Cambio de identidad" resume este tipo de situaciones:

si sembrás café te acusarán de formar una oligarquía
judía. Si sos trabajador, y se te ocurre participar en
una huelga, te dirán judeo-comunista. Metido en el
comercio, estás robando la plaza de un costarricense
de pura cepa. Como profesional, sos el que se
apodera de los mejores puestos" $\left(74^{14}\right)$.

El narrador denuncia un procedimiento común del discurso racista: culpar a la víctima (Stam y Sohat, 2002: 42). En doble ironía situacional, y aunque lucha como cualquier costarricense, el protagonista del cuento sufre el exilio identitario por ser judío, y una vez terminada la contienda civil, el exilio político por pertenecer al bando perdedor.

El narrador también enfrenta una situación paradójica (contradicción entre el ser y el parecer) al alistarse y participar en las filas del ejército progubernamental sin creer en su ideario de lucha. Joven impulsivo, sus expectativas quedan rápidamente defraudadas: la guerra se muestra como una sucesión de acontecimientos mezquinos y crueles, frente a la imagen romántica de la heroicidad. Reflexiona, en suma, sobre la ironía de la guerra como fenómeno moral, por ejemplo, sobre las etiquetas, mutuamente contradictorias que puede recibir un mismo individuo, según haya matado en 
tiempo de paz o de guerra: "[La guerra] te da licencia para asesinar. En tiempo de paz me habrían condenado como a un criminal." (81). Asimismo, reflexiona sobre la acción de matar a los soldados enemigos: “¿Era culpable de ese asesinato involuntario o podía considerarme héroe por liquidar a dos desconocidos en el frente de batalla, tal vez soldados de mi propio bando?" (87). La búsqueda de una explicación se resuelve en una aporía, en la ausencia de una solución para el dilema moral que encara.

Al finalizar el conflicto bélico, en lo que se conoce como inversión de papeles, se convierte en un enemigo de la patria, desde el punto de vista del bando vencedor. Una vez exiliado en Latinoamérica, su participación previa como soldado del ejército gubernamental en la Guerra del 48 le sigue como una sombra, allá donde intente radicarse como un civil que sólo desea labrarse un futuro profesional. Su pasado le persigue como una maldición o condena -la ironía del destino- de la que es imposible desprenderse. Una de las modalidades típicas de la ironía situacional consiste en que, después de una primera desgracia, y cuando el individuo espera mejorar, se concatenan inesperadamente nuevas situaciones negativas, errores o equivocaciones. El malentendido del que es víctima el narrador de "Cambio de identidad" consiste en que los gobiernos de los países en los que se radica le consideran un eficaz paramilitar que pueden contratar a su servicio. Debe abandonar Nicaragua, una vez que tratan de enrolarle los grupos de apoyo a la invasión de este país. Al radicarse en Venezuela, huye del país cuando la policía secreta pretende incorporarle en sus proyectos represivos. La ironía que vive en el extranjero consiste en que debe ocultar, infructuosamente, una identidad la de 'sicario' - a la que nunca perteneció.

Al narrador le queda, en todo caso, un único refugio. Sin Patria, sin hogar nacional, exiliado en Los Ángeles (que junto con Nueva York es la ciudad por antonomasia de los inmigrantes), cuenta con la protección del hogar familiar que ha formado lejos de Costa Rica. Las palabras que dirige al innominado oyente o narratario, situadas al final del cuento, son simbólicamente importantes, más allá de su aparente intrascendencia: "Ahora vamos a casa, que quiero presentarte a Shirley." (91). Frente a un hogar nacional que le han negado (Costa Rica), su único refugio -su único sentido de pertenencia-, sólo lo podrá encontrar en el espacio identitario privado del hogar familiar.

\section{Conclusiones}

La ironía de situación que sufre el protagonista del cuento en "Delicias del vuelo" se puede identificar narrativamente como la sucesión ininterrumpida, en un corto espacio de tiempo, de situaciones imprevisibles e incómodas, al convertirse una belleza contemplativa en una máquina parlante Bergson, como ya vimos, se refiere a esta situación desde la imagen de la bola de nieve, mientras que Lucariello (1994: 132), en el marco de las 28 posibilidades de ironía situacional que propone, se refiere a la posibilidad de que una víctima repita una situación de pérdida (loss) altamente improbable. Esta pérdida, incomodidad, desgracia o molestia, como también podemos llamarla, puede aparecer más de dos veces, contra lo que cree Lucariello. Es lo que llamamos en el lenguaje popular con el enunciado 'las desgracias nunca llegan solas', o 'tras cuernos, palos'. Cuando esperamos mejorar después de un contratiempo, contra todo pronóstico sufrimos seguidamente una cantidad alta de desgracias en tan poco tiempo, que esta concatenación se encuentra en el límite de la verosimilitud.

"Cambio de identidad" nos ofrece la ironía de situación como una serie de situaciones paradójicas que un costarricense judío $-\mathrm{y}$, por lo tanto, integrante de una minoría- enfrenta en la Costa Rica políticamente convulsa de mediados del siglo XX. Se ve en la incapacidad de controlar los acontecimientos, de fijar su sentido, cuando el entorno social se torna hostil, en las dos situaciones paradigmáticas ofrecidas por el cuento, la guerra y el exilio. Si tomamos en cuenta las vicisitudes de su protagonista como 
representativas de la condición de persecución y exilio permanente del pueblo judío en Occidente, se ve obligado a abandonar una tierra que, paradójicamente, fue en sus inicios un espacio de acogida. Como concluye Barahona (2003: 24), para la comunidad judía "Costa Rica también fue considerada un Paraíso, aunque este deseo fracasó."

En futuras investigaciones se puede analizar la utilización de la ironía situacional en otros cuentos de Rovinski. Como sugerencia, expongo el caso del cuento "Madre querida", de El embudo de Pandora (1991). En este relato, la ironía de situación se ofrece mediante el contraste ofrecido por la cotidianeidad laboral de un 'perdedor', empleado amargado de una financiera situada en el degradado centro josefino, y sus planes para ser propietario de una cantina, una vez que logre convencer a su madre enferma de vender la casa que ambos habitan. La yuxtaposición de dos situaciones completamente contradictorias -por un lado, la asfixiante situación cotidiana del protagonista, tanto laboral como familiar, y por otro lado la seguridad prepotente con la que imagina el cumplimiento de sus egoístas ilusiones-, permite comprender al lector que sus expectativas de comprar una cantina, nunca llegarán a materializarse.

\section{Notas}

1. La Nación, 9.12.2009: 2A; publicada originalmente el 9.12.1959.

2. La Nación, 10.11.2009: 2A; publicada originalmente el 10.11.1959.

3. La Nación, 23.12.2009: 2; noticia publicada originalmente en el 23.12.1959.

4. Esta definición de la ironía situacional queda ilustrada en los ejemplos ofrecidos en la canción "Ironic", de Alanis Morissette, el primero de ellos sobre un hombre de noventa y cuatro años que se gana la lotería y muere al día siguiente. Este hombre, y con él cualquier individuo, tiene la expectativa de disfrutar, por lo menos durante un plazo largo, del dinero ganado en la lotería, situación que no tendrá lugar.

5. Schoentjes (2003: 48-49) distingue la ironía situacional narrativa de la pictórica, que involucra situaciones que muestran en la misma imagen dos elementos contradictorios relacionados. Prefiero llamar a la ironía situacional que Schoentjes define como pictórica con el nombre de ironía descriptiva. Suele aparecer en imágenes (por ejemplo, en fotográficas). En particular, el marcador identificador de este tipo de ironía es el de la yuxtaposición: en una fotografía, el mall (símbolo de consumismo) aparece al lado de un precario (símbolo de pobreza y de la distribución desigual e injusta de la riqueza social).

6. No hay que confundir este sentido de inversión con el de las imágenes de inversión utilizadas en la cultura carnavalesca.

7. No debe extrañar el uso de este mecanismo narrativo en la llamada prensa sensacionalista. Este último tipo de prensa siempre pretende llamar la atención, despertar la curiosidad, del lector.

8. La teoría del script o guión se ha consolidado en las últimas décadas en la lingüística y en la narratología, y la teoría sobre la ironía situacional no es la excepción.

9. Además, Lucariello identifica siete tipos de ironías situacionales y, dentro de ellas, un total de 28 modalidades.

10. Como observa De Man (1991: 235), y en esto sigue a Baudelaire, la conciencia irónica es producto del desdoblamiento: "al utilizar el concepto de superioridad cuando el sujeto entra en relación no con otro sujeto sino con lo que precisamente no es sujeto [ya que al desdoblarse, su otro, el que es objeto de burla, es asumido como un objeto externo], entonces dicha superioridad no hace más que designar la distancia constitutiva de todo acto de reflexión."

11. A partir de este momento, toda cita de este cuento procede de la siguiente edición: Samuel Rovinski. El embudo de Pandora. San José, Costa Rica: Editorial Costa Rica, 1991.

12. Curiosamente, y como coincidencia, tanto en el cuento de García Márquez como el de Rovinski, el vuelo sale del aeropuerto parisino Charles de 
Gaulle, aunque en el primer caso tiene por destino Nueva York y, en el segundo, Washington. Aunque parezca un dato irrelevante, la cercana inauguración del aeropuerto francés, ocurrida en 1974, pudo haber motivado a estos escritores, así como posiblemente a muchos otros, a utilizarlo en sus ficciones, siempre que un personaje tuviera que viajar en avión de Europa a América.

13. Se puede consultar en: Edgar Allan Poe, Obras en prosa, I y II (Traducción, introducción y notas de Julio Cortázar). Madrid: Universidad de Puerto Rico/Revista de Occidente, 1956.

\section{Bibliografía}

Aristóteles. 1994. Poética. Barcelona, Editorial Icaria.

Barahona, Alberto. 2003. "El desdoblamiento cultural de la sociedad costarricense en un texto de Samuel Rovinski", Revista de Filología y Lingüistica de la Universidad de Costa Rica, 2003, XXIX (2), 7-25.

Barahona, Alberto. 1991. Cuentos judios de mi tierra: o el viaje interminable de la identidad versus la alteridad. Tesis para optar por el grado de Licenciado en Filología Española. San José: Costa Rica.

Baudelaire, Charles. 2001. "Esencia de la risa $\mathrm{y}$, en general, de lo cómico en las artes plásticas". En: Pequeños poemas en prosa. Críticas de arte. Madrid: Editorial Espasa-Calpe.

Bergson, Henri. 1973. La risa. Ensayo sobre la significación de lo cómico. Madrid: Espasa-Calpe.

Cuvardic García, Dorde. "Marcadores de ironía en el discurso informativo de la prensa costarricense",", Actas del Simposio sobre ironía y humor, Universidad de Alicante, 15 y 16 de diciembre, 2011. Alicante: Servicio de publicaciones de la Universidad de Alicante (en prensa para el 2013).

De Man, Paul. 1991. Visión y ceguera. Puerto Rico: Universidad de Puerto Rico.

Ducrot, Oswald. 1986. El decir y lo dicho. Polifonía de la enunciación. Barcelona, Paidós.

García Márquez, Gabriel. 1997. "El avión de la bella durmiente". En: Doce cuentos peregrinos. Bogotá, Colombia, 61-69.

Li, Xiang Li. 2008. "Irony Illustrated:A CrossCultural Exploration of Situational Irony in China and the United States", SINOPLATONIC PAPERS, 184, 1-65.

Lucariello, J. 1994. "Situational irony: A concept of events gone awry", Journal of Experimental Psychology (123), 129-145.

Poe, Edgar Allan. 1956. Obras en prosa, I y II (Traducción, introducción y notas de Julio Cortázar). Madrid: Universidad de Puerto Rico/Revista de Occidente.

Roca Marín, Santiago. 2009. "Ironía e interculturalidad". En: Leonor Ruiz Gurillo y Xose A. Padilla García (eds.). Dime cómo ironizas y te diré quién eres. Una aproximación pragmática a la ironía. Frankfurt am Main: Peter Lang.

Rovinski, Samuel. 1991. El embudo de Pandora. San José, Costa Rica: Editorial Costa Rica.

Rovinski, Samuel. 1982. Cuentos judios de mi tierra. San José, Costa Rica: Editorial Costa Rica.

Schoentjes, Pierre. 2003. La poética de la ironía. Madrid, Editorial Cátedra. 
Shelley, C. 2001. "The bicoherence theory of situational irony," Cognitive Science (25), $775-818$.

Sperber y Wilson (1994): La relevancia. Madrid, Visor.
Stam. Robert y Ella Sohat. 2002. Multiculturalismo, cine $y$ medios de comunicación. Crítica del pensamiento eurocéntrico. Barcelona: Editorial Paidós.

\section{(c) $(\mathbb{8} \Theta \Theta$}

Este obra está bajo una licencia de Creative Commons

Reconocimiento-NoComercial-SinObraDerivada 4.0 Internacional. 